\title{
Text and discourse models as knowledge formats
}

\author{
E.A. Ogneva*, E.N. Musaelian, D.E. Smirnova, I.A. Danilenko, and M.O. Sushenok
}

Belgorod National Research University, 308012 Belgorod, Russia

\begin{abstract}
Knowledge format is a construct for information storing, accumulating, transmitting. Text and discourse are studied as main knowledge formats. Previous studies have found the literary text is defined as a product of writer's speech-thinking activity. Discourse is interpreted as a text immersed in a communicative situation. The construction specific features of text and discourse are revealed through their modeling as an objective way of knowledge formats architectonics visualising. Literary text is considered in the form of conceptual domain as a set of literary concepts wich are correlated with writer's text world. There are two types of writer's text world models such as monomodel and polymodel. It is proved that monomodel text world is the plot-thematic unity of all literary conceptual domain which the writer creates. The polymodel text world consists of the plot-thematic correlation of literary dominant concepts formed according to different themes. Both monomodel and polymodel text worlds are the base for literary discourse forming. Monomodel text world is the base for monomodel literary discourse. Polymodel text world is the base for polymodel one's. The research of text and discourse models of knowledge formats is the optimal interpretative way to discover the patterns of knowledge existence.
\end{abstract}

\section{Introduction}

The study of linguistic knowledge is a multi-level complex process. In such process the knowledge format is one of the basic components. The knowledge format is understood as a research construct systematising a certain segment of general knowledge. According to N.N. Boldyrev, the knowledge format should be understood as "a certain form of representing knowledge at the thought (conceptual) or language levels" (Boldyrev 2009).

There are different knowledge formats which can be divided into two types: conceptual simple knowledge formats and conceptual complex knowledge formats. The conceptual simple type of knowledge formats consists of concepts having elementary structures such as a sensual image, scheme, representation, prototype. The conceptual complex type of knowledge formats consists of conceptual structures such as: (a) stereotypical knowledge structures, i.e. frames, propositions; (b) knowledge structures of categorical format, (c) multidimensional knowledge structures (Boldyrev 2009).

\footnotetext{
*Corresponding author: ogneva@bsu.edu.ru
} 
The conceptual complex type of knowledge formats consists of both text and discourse. The text as a format of the writer's text world has a complex structure. Many researchers from different countries study the specific features of text as complex structure such as L.G. Babenko (2004), F. Cramer (2001), J. Cuddon (1992), G. Currie (2007), T. Eagleton (2008), T. Eaton (2008), I.R. Galperin (2007), Hirsch (1997), M. Klarer (2011), M. Lotman (1998), P. Macherey (2006), R. Selden, P. Widdowson. P. Brooker (2005), N.S. Valgina (2003), S. Zunshine (2006), etc.

There are various text definitions, but the relevant definition for this study is to consider the text as a product of rhetoric activity as a synergy of the multi-vector aspects of people being. In this case the text structure seems as the writer's refraction. The text structure is a complex, holistic cognitive-discursive formation of a linear nature. All components in the text structure represent the commutative intension of the writer in the form of a united hierarchically organised structure.

In this research way the text, especially literary text, is a set of nine categories such as multi-components, cohesion, continuum, informativeness, retrospection, prospecting, modality, integration and completeness (Galperin 2007: 26-125).

As a knowledge format the literary text, i.e. its cognitive plot matrix is a conglomerate of deep ethnic people thoughts in the refracted projection of the writer's worldview. The literary text should be considered as a creative linguistic structure of reality as a representative symbol of the synergy of the past, present and future of people being. Such kind of people being synergy verbalises through language signs, thus forming the literary world. "The model of the literary world is in the epicenter of different types' research such as linguo-cognitive, linguo-cultural and other ones" (Ogneva 2014: 551), because literary text generation “doesn't begin with a logically pronounced "textual theme", but with a capacious symbol which gives the planform for diverse interpretations" (Lotman 1998: 104). This point of view is the base to determine the relationship between intentionality and interpretation (Levinson 2007).

Thera are some other points of view for text structure.

Firstly, P. Macherey paid attention to some important text components such as (a) positive and negative judgments of the writer, (b) improvisation of the writer, (c) structure and patterns of text construction, (d) depth and complexity of text construction (Macherey 2006).

Secondly, R. de Beaugrande and W. U. Dressler paid attention to seven constitutive text properties such as cohesion, coherence, intentionality, perception, situativity, informativity, intertextuality (de Beaugrande, Dressler 1981). Later these scientists proved seven textuality standards such as unity, coherence, intentionality, acceptability, informational content, conditionality of the situation, intertextuality (de Beaugrande, Dressler 2004).

Thirdly, F. Cramer focused on the relationship between digital code and the structure of the literary text (Cramer 2001).

Fourthly, M. Klarer outlined the specific features of textual-oriented, writer-oriented and reader-oriented approaches to the text studies (Klarer 2011).

Fifthly, Slovak linguist N.I. Panasenko draws attention to the fact that "the study of the text as an independent linguistic object with special features of semantic and structural organisation makes the base to divide the text into phrase units" (Panasenko 2006: 396).

There are many other text structure interpretations too.

Study of the text structure is very important because the text is the kernel of the text world interpreted as the informative being which is formed around the text (Semino 2009). The discourse is interpreted as a text immersed into a communicative situation (Alefirenko 2014). Discourse is multifaceted in its nature. According to N. F. Alefirenko discourse can be interpreted as "a rethinking formation of event character" (Alefirenko 2009: 248). Another Russian scientist V. Z. Demyankov defines discourse as speech in its formation. 
As a result, the reference ambiguity is eliminated, and the communicative purpose of each sentence is determined step by step (Demyankov 2007).

V. I. Karasik understands the discourse as text immersed into a situation of communication, allowing "multiple measuring" and complementary approaches in the way of pragmalinguistics, psycholinguistics, structural linguistics, linguocultural studies, sociolinguistics (Karasik 2000). It should be said that "the contemporary discourse paradigm of knowledge is represented by a wide conceptual spectrum from the discourse consideration as a text to the study of this phenomenon as a communicative event" (Ogneva 2015: 569). Discourse is correlated with "communication behavior and national language" (Sedykh et al 2019: 9039).

A comprehensive study of both text and discourse implies their modeling with the purpose to determine the deeper meaning of the literary text (Langer 2010, Levine, and Horton 2013). Complex modeling of both text and discourse as knowledge formats is one of the current areas in contemporary linguistics.

\section{Methods}

A new level of both text and discourse analysis evolution requires new methodological developments, which, along with previously developed methods, are aimed at solving urgent problems. One of the urgent problems is the development of strategic algorithms for both text and discourse modeling. Thus, the author's matrix methodological approach to the study of factual material contributes to the comprehensive consideration and modeling of both text and discourse, identifying problems and prospects of its development as a dynamic system.

The use of the author's algorithm for predicting the degree of both text and discourse modifications and cultural discursive patterns is aimed at identifying their synergising in the models having different themes. The interpretation of these models as knowledge formats discovers the rules of world conceptualisation in both literary text and discourse.

\section{Results}

In contemporary linguistics there are prerequisites for the new theory forming, i.e. the theory of model linguistics. According to K.I. Belousov

"the new linguistic theory is not just a system of quantising methods and techniques, but a system of views on the organisation of language reality's research. Such kind of research

bases on methods for obtaining, storing and exchanging data, methods of statistical

analysis and computer modeling, interpretation of results and the ability to reproduce them» (Belousov 2010: 96-97).

The formation of a new theory in linguistics is due to the change of the research vector from "description" to "modelability", so "the consequence of the guiding line changing is the purpose to research the reliability, quantifiability and prognostic nature of the created language models" (Belousov 2010: 94).

Modeling identifies as a complete activity program consisting of a consistently applied set of methods and techniques aimed at a systematic representation of any subject or object area. In the proceedings of I.A. Schirova "modeling is ranked among the main principles of cognitive sciences" (Schirova 2013: 42).

V.A. Shtof writes that 
«the model is understood as such mentally represented or materially realised system that displays or reproduces the object of research. This system is able to be replaced. So, the study of this system gives us new information about the object» (Shtof 1966: 19).

Later R.G. Piotrovsky emphasises the fact that models can serve as a means of studying or describing of the internal structure of original things. Such models are named structural models. There are some models for describing of original things behavior, i.e. functional models. There are some models for describing of original things' development, i.e. dynamic models (Piotrovsky 1998: 86-96).

V.I. Karasik clarifies the model "as a research construct of reality. Such construct is a way for studying of any essence in its system and functional relations with phenomena of more general order" (Karasik 2013: 6). It should be taken into account the relationship between categories and cognitive models (Lakoff 1984).

Obviously, the modelability property of reality in both text and discourse formats is considered to determine the interpretive cognitive-logical principles of the functioning of sign models. The totality of sign models as writer's projection of the real world is embodied into the literary text. Such literary text is generated by writer's imagination. This kind of text acts as a means of writer's worldview objectification in the conceptual system.

Specific features of text conceptual system form the text model as one of the forms of culturally conditioned "mental models" (Johnson 1983, Croft, Cruse 2004) as "mental spaces" (Fauconnier 2014). In such case, text model is the base for discourse model forming. Applying of model linguistics postulates to both text and discourse as knowledge formats leads to the fact that both text and discourse become more accessible to perception through interpretation.

So, first of all, we describe the modeling specific features of text as a knowledge format. The text modeling is based on the fact that "the hermeneutic text model is traditionally opposed to its structural-semiotic interpretations" (Schirova 2014: 165). Such text opposition correlates with interpretation of text and world interconditionality (Goodman, Elgin 2007).

P. Ricoeur pays attention to interpretation as "a symbol which makes to think. Such symbol provokes interpretation just because it says more about reality" (Ricoeur 2002: 60). E. Knipkens and R. Zwaan draw attention to the fact that the text understanding is based on two aspects such as emotional aspect and cognitive ones (Knipkens and Zwaan 1995).

In this way F. Schleiermacher's says that "the literary idea is a will as the base of writer's idea. Such literary idea can be understood by correlation with the material and the influence sphere" (Schleiermacher 2004: 156-157). Such literary idea affects the types of text as the basic discourse components. In this case the discourse parameters are caused by writer's text world (Hidalgo 2000).

Discourse model is caused by the text. According to N. Tincheva "some scholars approach text type as text structure-oriented and dependent on linguistic properties" (Tincheva 2017: 85). Meanwhile, the number of scientists state that the complexity of the text type is the base for multiple interpretations of it (e.g. Lee 2001, Beaugrand de 2004), because "text type as an abstract category designed to characterise the main structure of a particular text or one of its parts according to its dominant properties" (Aumüller 2014: 854). N. Tincheva emphasises "another important aspect to note with respect to the notion of text type is its interconnection with another frequently debated notion - the one of the genres" (Tincheva 2017: 89). The genre of the text can be interpreted as the format of "prototypes" (Hyvärinen 2012).

A scientific search within the field of text modeling has contributed to the emergence of research in different formats. First of all, the principles of cognitive processes in the language modeling in English-language psychological prose of the 20th century are substantiated (Schirova 2001). Then the principles of semantic modeling in linguo- 
metaphorological research are stated (Aleshina 2003). Later the existence of some modeling types such as "conceptual taxonomic modeling or conceptual taxonomic analysis, cognitive-matrix modeling or cognitive-matrix analysis" are substantiated (Boldyrev 2009).

Also, in contemporary linguistics there are the following text modeling types such as syntax text modeling, causal-genetic text modeling, linguosociocultural text modeling, etc.

Syntax text modeling is an interpretation of the syntax constructions' formats forming the text framework as a form of practical implementation of communicative target settings, which allow to visually imagine the logic and dynamics of the story narrative development.

Causal-genetic text modeling is being seen as a research approach which allows to conduct comprehensive texts studies using discourse analysis. Causal-genetic text modeling allows to consider any text (oral or written) as a complex linguistic sign. The content of this linguistic sign is represented in four dimensions: structural, system, hierarchical, linear.

Linguosociocultural text modeling is aimed at studying of sociocultural knowledge representations' form of the text.

Obviously, the presented text modeling types are non-exhaustive. Search for new text modeling methods continues. We develop a complex text modeling algorithm to interpret nine text categories according to I.R. Galperin's classification of them (Galperin 2007).

Firstly, the text modeling at the level of multi-components text category is based on three aspects of text parameters such as (a) a subjective nature due to the writer's intention, (b) multi-components text parameter is objectively due to the need to reflect the order of the world, (c) multi-components text parameter has a structural and cognitive basis. Modeling text at this level is based on interpreting of sentences as the base of the text.

Secondly, the text modeling at the level of the cohesion category is carried out taking into account the text-forming potential of cohesion in the forming field of the structural and semantic integrity of the text. This kind of text modeling is carried out through the interpretation of the mechanisms of mutual conditionality of the structural and semantic integrity in the literary text. The fact is taken into account that the choice of structure for the implementation of the text plot meaning is due to the writer's intensity. Such kind of intensity is based on the text perception, i.e. writer's intensity correlates with the text addressee's intensity.

Thirdly, text modeling at the level of the continuum category is based on specific features of continuum, i.e. a united plot motion stream in time and space. Text continuum research leads to text dynamic 3D modeling. This kind of text modeling means the forming of dynamic graphical text model. According to our text modeling conception a dynamic graphical text model means a sequential combination of n-number of graphic research constructs. Every graphic research construct reflects the part of the dynamic process of the writer's thought movement in the plot time and in the plot space.

Fourthly, text modeling at the level of text informativity category is based on the degree of meaningful text novelty for the reader. This text novelty is contained in the theme and the writer's concept of the text-plot. Modeling of the meaningful plot novelty is based on the interpretation of the results of text addressees' survey. Such kind of survey aims to identify kernel and peripheral components of the plot novelty.

Fifthly, text modeling at the level of the text retrospection category is based on the interpretation of the plot-temporal text aspect. Text retrospection category identifies as a compositional method of returning into past time in the plot. The plot-temporal aspect is a unit of different temporal markers such as chronemes, lexical timers, tenses. Chronemes are language units; their semantics expresses time parameters. Lexical timers are words and phrases; their semantics of time parameters are implicit. Tenses identify the time of somebody's act describing in the text.

Sixthly, text modeling at the level of the prospecting category is based on predicting of the plot. This text modeling type is based on the identification, description, determination 
of the introductory unit's frequency using for prospecting. The introductory units are such as in future, the following can be said, and etc.

Seventhly, text modeling at the level of the modality category is based on the identification, and description of words and phrases frequency representing the modality of the text. Text modality means as the writer's attitude to the plot.

Eighthly, text modeling at the level of the integration category is based on plot-forming framework of text which is created by identifying of the plot-forming thematic kernels. The text integration category is a category describing the unit of text parts in order to create whole text. This level of text modeling is considered as the unit of attractors of reader's attention.

Finally, text modeling at the level of the text completeness category is based on the identification and interpretation of text units for representation of completeness. The text completeness means as a function of plot. It should be noted that some literary texts haven't the completeness category.

So, the unit of nine text categories' models creates the complex model of cognitive-plot matrix of the literary text which refers to a comprehensive text model of a real or fictional world represented by the writer in the literary text. The model parameters are caused by the writer's worldview, and his thematical ideas realised in the literary text.

Studies of the complex model of cognitive-plot matrix's architecture revealed that matrix parameters are set by the writer's worldview, and the goals of literary text creating. The writer's worldview determines the parameters of the writer's text world as a set of literary symbols. This set of literary symbols creates the cognitive-plot corpus to form the literary conceptual domain as a set of literary concepts.

According to L.V. Miller

«a literary concept is a complex mental image which is not belonging only to individual writer's consciousness, but also to the $<\ldots . .>$ psychomental sphere of a certain

ethnocultural community. The literary concept is a universal literary experience fixed in cultural people memory and forming new literary sense» (Miller 2000: 42).

The literary concept could be interpreted as a component of the literary conceptual domain including those mental signs and phenomena which are preserved by the historical memory of the people. They are cognitively pragmatic things in the writer's mind for the development of the plot. Literary concepts represent the synergy of the past, present and future of people into the text knowledge formats as projection of writer's text world.

Comprehensive studies of the text worlds of various writers discovered that the writer's text world can be both a monomodel format and a polymodal format. The monomodelity of the writer's text world is due to the plot-thematic unity of all literary conceptual domains of the writer. The polymodelity of the writer's text world is due the plot-thematic conjugation of all conceptual domains of the writer.

Monomodelity of the writer's text world is based on the identity of the themes and the plot construction of all writer's works. Studies discovered that monomodelity of the writer's text world means that there are several same dominant concepts in all literary conceptual domains of the writer. Such several same dominant concepts form the cognitive-plot matrix of the writer's text world. Dominant concepts mean as plot-forming literary concepts. It is proved that in all literary conceptual domains of the monomodel text world of the writer there are the identical literary dominant concepts.

Polymodelity of the writer's text world is based on conjugation of the conceptual domains, i.e. some literary dominant concepts are identical in writer's text world, but most of dominant concepts of the writer's text world have different themes.

Studies discovered that two types of text worlds such as the monomodel text world and the polymodel text world lead to the formation of a monomodel literary discourse or 
polymodel literary discourse. The model of literary discourse is a unit of several components both the addressee and the sender who identify as communicants forming the literary discourse, i.e. readers are addressees and writers are senders. Along with communicants in the model of literary discourse there is the subject of communication, i.e. the literary text as a projection of the writer's worldview. There are some rules of literary discourse formation. Firstly, if the parameters of literary text conceptual domain correlate with the monomodel text world of the writer, then a monomodel literary discourse is created on its basis. Secondly, if the parameters of literary text conceptual domain correlate with multimodel text world of the writer, then a multimodel literary discourse is created on its basis. In such way "a discourse matrix sociomodel can be represented in the form of a dynamic discursive formations" (Ogneva et al 2018).

Studies discovered that monomodelity and polymodelity of literary discourse are the results of various interpretations of the texts due to the parameters of language personalities of various readers. It is proved that multimodel literary discourses will quantitatively prevail over monomodel literary discourses.

\section{Discussion and conclusion}

Modeling of linguo-cognitive constructs in both text and discourse expands interpretative horizons of contemporary linguistics. In this case, interpretation is understood "as the linguistic cognitive activity of a person. The result of text interpretation identifies subjective understanding of the interpretation object" (Boldyrev 2015: 7) in the process of modeling.

Both literary text and discourse formats mean as symbolic interpretative models. The process of symbolic interpretative models' formation is ensured by the fixation of the properties of extra-linguistic reality by a system of discrete language signs.

The cognitive structure of both literary text and discourse models mean as a system of discrete language signs too. These discrete language signs are the set of values reflecting the properties of reality in the both literary text and discourse. So, the research of both literary text and discourse models presenting different types of knowledge formats is one of the main modeling problems. In such case, it should pay attention to the fact that "readers willingly draw interpretive conclusions" (McCarthy, Goldman 2017: 4).

Consideration of cognitive-discursive reality in the form of projection knowledge formats as complex multifaceted constructs creates broad interpretative perspectives for both text and discourse. The architectonics of projection knowledge formats are as the writer's refraction of reality as the reader's text interpreting.

Thus, both the monomodel and the polymodel of the literary text world and discourse lead to the development of the interpretative field of the text projection of the world. In this field some literary concepts acquire the status of dominant concepts.

It is proved that the monomodelity of writer's text world bases on the identical literary dominant concepts. Such kind of literary text world is the base for forming of monomodel literary discourse. The polymodality of writer's text world bases on conjunction of some identical literary dominant concepts and dominant concepts with different thematic kernels. This kind of text world model is the base for polymodel literary discourse. Consideration of both text and discourse architectonics in the form of monomodels or polymodels contributes to create the interpretative complex multivector constructs as formats of socially significant knowledge.

Both text and discourse modeling don't reveal only the surface text matrix, but the deep matrix of text architectonics too. In such case, both text and discourse modeling contribute to the interpretative representation of humanitarian knowledge process. 


\section{The Conflict of Interest Statement}

In line with the statement of Committee on Publication Ethics (COPE), we hereby declare that we had no conflicting interests regarding any parties of this study.

\section{References}

1. N. F. Alefirenko, Alive Ward: Issues of Functional Lexicography (2009)

2. N. F. Alefirenko, X Linguae, 2, 32 (2014)

3. O. Aleshina, Semantic Modeling Linguomethaphorological Rresearch: Based on Russian (2003)

4. M. Aumüller, Handbook of Narratolog, 854 (2014)

5. L. Babenko, Philological Analysis of Text, Theory Basis, Principals, and Aspects of Analysis (2004)

6. R. Beaugrande, W.U. Dressler, Einführung in die Text linguistic (1981)

7. R. Beaugrande, A New Introduction to the Study of Text and Discourse (2004), http://beaugrande.com/

8. K.Belousov, Vestnik of Orenburg State University, 11(117), 94 (2010)

9. N.Boldyrev, Cognitive Studies of Language (2009)

10. N. Boldyrev, Issues of Cognitive Linguistics, 1, 5 (2015)

11. F. Cramer, Hypermedia Literary Journal (2001) http://www.dvara.net/

12. W. Croft, A. Cruse, Cambridge: Cambridge University Press (2004)

13. J. Cuddon, The Penguin Dictionary of Literary Terms and Literary Theory (1992)

14. G. Currie, Work and Text. Philosophy of Literature. Contemporary and Classic Readings. An Anthology, 98 (2007)

15. V. Demyankov, Paper presented the 4th International Conference Language, culture, society (2007)

16. T. Eagleton, Literary Theory. An Introduction (2008)

17. T. Eaton,Literature Semantics (2010)

18. G. Fauconnier, The New Psychology of Language: Cognitive and Functional Approaches to Language Structure (I), 230 (2014)

19. I. Galperin, Text as the Object of Linguistic Research (2007)

20. N. Goodman, K. Elgin, Philosophy of Literature, Contemporary and Classic Readings, 93 (2007)

21. L. Hidalgo, Negation, Text Worlds, and Discourse. The Pragmatics of Fiction (2000)

22. E. D. Hirsch, Twentieth-Century Literary Theory. A Reader, 51 (1997)

23. M. Hyvärinen, Narrative Works: Issues, Investigations \& Interventions, 2/1, 10 (2012)

24. Ph. Johnson-Laird, Mental Models, Towards a Cognitive Science of Language, Inference, and Consciousness (1983)

25. V. Karasik, Language personality: institutional and personal discourse, 5 (2000)

26. V. Karasik, Language Matrix of Culture (2013)

27. M. Klarer, An introduction to Literary Studies (2011)

28. L. Kneepkens, R. Zwaan, Poetics, 23(1-2), 125 (1995)

29. G. Lakoff, Berkeley Cognitive Science Report, 275 (1984) 
30. J. Langer, Envisioning Literature: Literary Understanding and Literature Instruction (2010)

31. D. F. N. Lee, Language Learning \& Technology, 5/3, 37 (2001).

32. S. Levine, W. Horton, Scientific study of literature, 3, 105(2013).

33. J. Levinson, Philosophy of Literature. Contemporary and Classic Reading. An Anthology, 98 (2007).

34. Y. Lotman, About the Art (1998)

35. P. Macherey, Theory of Literary Production (2006)

36. K. McCarthy, \& S. R. Goldman, Constructing Interpretive Inferences about Literary Text: The Role of Domain-Specific Knowledge (2017)

37. L. Miller, World of Russian Ward, 4, 41 (2000)

38. E. Ogneva, Cognitive Studies of Language, 550 (2014)

39. E. Ogneva, Transformation of Socium Discourse Model: Problems and Perspectives, The International Conference Risks in changeable social reality: problem of prediction and management. Russian: Voronezh: OOO "PT", November (2015)

40. E. Ogneva, D. Nikulina, E. Musaelian, R.E. Bogachev, A. Kutsenko, I. Danilenko,. Journal of History Culture and Art Research, 7(2), 729 (2018)

41. N. Panasenko, Semantic Space of Literary Text. The $9^{\text {th }}$ International Conference Semantic of Speech and Text. Ukraine: Ivano-Frankivsk. September (2006)

42. R. Piotrovsky, Issues of Roman and General Linguistics, 86 (1998)

43. P. Ricoeur, Conflict of Interpretations (2002)

44. I. Schirova, Language Modeling of Cognitive Processes in English Psychological Prose of $20^{\text {th }}$ century (2001)

45. I. Schirova, Text Through the Prism of Complex (2013)

46. I. Schirova, Vestnik of Leningrad State University named after A.S. Pushkin. 7, 1, 163 (2014).

47. F. Schleiermacher, Hermeneutics (2004)

48. A. Sedykh, Zh. Yonghua, D. Shchukina, O. Vorobeva, S. Nikonov, International Journal of Recent Technology and Engineering, 4, 9039 (2019)

49. R. Selden, P. Widdowson, P. Brooker, Reader's Guide to Contemporary Literary Theory (2005)

50. E. Semino, Cognitive Poetics: Goals, Gains, and Gaps (2009)

51. V. Shtof, Modeling and Philosophy (1966)

52. N. Tincheva, Discourse and Interaction, 2, 85 (2017)

53. N. Valgina, Text Theory (2003)

54. L. Zunshine, Why We Read Fiction Theory of Mind and the Novel (2006) 